\title{
The Role of the Chelating Agent on the Structure and Anticorrosion Performances of an Organosilane-Zirconium Sol-Gel Coatings
}

\author{
M. O'Sullivan'1, N. A. Odewunmi², M. Cullen'1, A. A. Sorour ${ }^{2,3}$, B. Duffy ${ }^{1}$, Z. M. Gasem ${ }^{2,3}$, M. Oubaha1 ${ }^{*}$ \\ ${ }^{1}$ Dublin Institute of Technology, Centre for Research in Engineering Surface Technology, Dublin, Ireland \\ ${ }^{2}$ Centre of Research Excellence in Corrosion, King Fahd University of Petroleum and Minerals (KFUPM), Dhahran, KSA \\ ${ }^{3}$ Department of Mechanical Engineering, King Fahd University of Petroleum \& Minerals (KFUPM), Dhahran, KSA \\ Email:*452818@dit.ie
}

How to cite this paper: O'Sullivan, M. Odewunmi, N.A., Cullen, M., Sorour, A.A., Duffy, B., Gasem, Z.M. and Oubaha, M. (2018) The Role of the Chelating Agent on the Structure and Anticorrosion Performances of an Organosilane-Zirconium Sol-Gel Coatings. Advances in Materials Physics and Chemistry, 8, 89-104. https://doi.org/10.4236/ampc.2018.82007

Received: December 15, 2017 Accepted: February 25, 2018 Published: February 28, 2018

Copyright $\odot 2018$ by authors and Scientific Research Publishing Inc. This work is licensed under the Creative Commons Attribution International License (CC BY 4.0).

http://creativecommons.org/licenses/by/4.0/ (c) (i) Open Access

\begin{abstract}
This work investigates the role of the structure of a zirconium complex (ZC) on the condensation and anticorrosion properties of an organosilane sol-gel coating. The structure and reactivity of the $\mathrm{ZC}$ were modified by varying the content of methacrylic acid employed as a chelating agent. The structures of the developed materials were characterised by Dynamic Light Scattering, Fourier Transform Infrared Spectroscopy, Differential Scanning Calorimetry and Scanning Electron Microscopy. The passive anticorrosion properties were evaluated by Electrochemical Impedance Spectroscopy of the sol-gel coatings deposited on AA2024-T3 substrates. It was highlighted, that a competition in the condensation process of the silicate $(\mathrm{Si}-\mathrm{O}-\mathrm{Si})$ and silicon- $\mathrm{ZC}$ oxides (Si-O-Zr) species can be tailored by the structure of the $\mathrm{ZC}$, with the least chelated ZC exhibiting the highest content of Si-O-Zr bonds. At the same time, it was also found that the coatings containing the highest content of $\mathrm{Si}-\mathrm{O}-\mathrm{Zr}$ groups exhibited the best anticorrosion barrier performances amongst all sol-gel coatings investigated here, therefore presenting the highest condensation degree. This suggested that Si-O-Zr bonds were the essential chemical species responsible for the formation of condensed coatings. A direct correlation between the structure of the coatings and their anticorrosion performances is proposed.
\end{abstract}

\section{Keywords}

Organosilane, Sol-Gel, Coatings, Corrosion, Structure, Condensation

\section{Introduction}

Eco-friendly coatings for the protection of metallic surfaces against environ- 
mental corrosion have been extensively investigated in the past decade to comply with environmental and health regulations, which limit the use of some heavy metals, such as hexavalent chromium [1] [2]. Recent reviews have comprehensively listed different process alternatives developed for the replacement of chromate coatings [3] [4]. These processes include anodization, passivation, chemical conversion, ion implantation, cathodic electrodeposition and sol-gel coatings. They are based on the use of individual chemistries such as trivalent chromium, phosphate, zinc phosphate, permanganate, rare earth metals, vanadium or combinations of these different compounds. Of these technologies, conversion coatings remain the cheapest and the easiest to process, while providing the mechanical and anti-corrosion properties required for industrial applications [5]. However, hybrid sol-gel materials have probably been the materials that have attracted the strongest interest from those listed above [6] [7] as a viable alternative, with organically modified silicate-based coatings being the most popular. The higher focus on these hybrid materials rather than the other listed alternatives is due to several factors. Firstly, a wide range of sol-gel reactive functionalised alkoxide silane precursors are commercially available, such as the acryloxysilanes, aminosilanes, epoxysilanes, cyanatosilanes, mercaptosilanes, vinylsilanes and alkylsilanes. In addition to their capability to form three-dimensional inorganic networks via the occurrence of hydrolysis and condensation reactions of the alkoxide groups, these precursors can provide functional groups at the surface of the coatings. For example, mercaptosilanes have been used to functionalise glass surfaces for the immobilisation of biological species [8], epoxysilanes have been employed to improve the adhesion properties of organic coatings [9] and acryloxysilanes have been used to provide photoreactivity for the fabrication of miniature devices [10] and microstructuring of optical devices [11]. Secondly, these organosilane sol-gel matrices are capable of hosting organic and inorganic doping elements to further provide desirable characteristics for specific applications. For example, inorganic inhibitors such as vanadates, molybdates, permanganates and cerium salts [12] [13], as well as organic inhibitors such as quinaldic acid, betaine, dopamine hydrochloride, diazolidinyl urea and tetrazines [14] [15] have been incorporated within silicate-based sol-gel matrices to improve their anticorrosion properties. Network modifiers such as transition metal alkoxides or ionic liquids have been incorporated within silicate-based materials to adjust the optical [16] [17], electrical [18] or surface morphology of inorganic surfaces [19].

Recently the authors have investigated the effect of the organosilane/transition metal (TM) ratio [20]. It was found that the concentration of the ZC and the hydrolysis degree has a significant impact on the formation of the siloxane and silicon-ZC oxide species as well as on the overall condensation of the hybrid sol-gel coatings and their anticorrosion performances. These studies suggested that the structure of the ZC may also impact the condensation process of the organosilane matrix with possible effects on the anticorrosion properties, which to our 
knowledge has not been reported previously. Therefore, this study aims at contributing to a better understanding of the role of the structure of transition metals in the condensation and passive anticorrosion properties of organosilane matrices. Here, the structure of the $\mathrm{ZC}$ was modified by addition of a chelating agent employed in different concentrations to form a $\mathrm{ZC}$ complex, in this way altering its reactivity towards the organosilane matrix. The developed materials were characterised by Dynamic Light Scattering, Fourier Transform Infrared Spectroscopy, Differential Scanning Calorimetry and Scanning Electron Microscopy. The passive anticorrosion properties were evaluated by Electrochemical Impedance Spectroscopy of the different materials deposited as thin films deposited on AA2024-T3 aluminium surfaces.

\section{Experimental}

\subsection{Materials Development}

The sol-gel materials were prepared from the mixture of an organosilane precursor (3-methacryloxypropyltrimethoxysilane, MAPTMS, Assay_99\% in methanol, Aldrich) and a zirconium complex prepared from the chelation of zirconium (IV) n-propoxide (ZPO, Assay 70\% in propanol, Aldrich) by methacrylic acid (MAAH, $\mathrm{C}_{4} \mathrm{H}_{6} \mathrm{O}_{4}$, Assay $>98 \%$, Aldrich). The choice of MAAH as a ligand chelating agent for ZPO was based on previous studies where this ligand was found to be the most adequate amongst a series of ligands used in the chelation of ZPO [21] [22]. In this study, the molar ratio of the ligand to the transition metal has been altered, keeping the molar ratio of the organosilane to the transition metal constant at 80:20 and the hydrolysis degree against the total number of alkoxide groups constant at 50\%, as summarized in Table 1.

Unlike organically-modified silicates, such as MAPTMS, transition metal complexes are unstable in presence of water forming spontaneously irreversible precipitates via condensation reactions. To avoid these undesired reactions and form a stable, clear and homogenous sol where the zirconium species can cohabitate with the silicate species within the same nanomaterial systems, the kinetic of hydrolysis of the zirconium alkoxide groups (to form the reactive zirconium hydroxide groups, $\mathrm{Zr}-\mathrm{OH}$ ) has to be controlled. To do this, a three-step sol-gel process has been established. 1) MAPTMS is hydrolysed employing an aqueous $\mathrm{HNO}_{3} \quad 0.1 \mathrm{~N}$ solution with a 1:0.75 ratio and ZPO is complexed with

Table 1. Materials formulations.

\begin{tabular}{ccc}
\hline Formulation & MAPTMS/ZPO/MAAH (mol. \%) & ZPO/MAAH \\
\hline A & $80 / 20 / 5$ & $1 / 0.25$ \\
B & $80 / 20 / 10$ & $1 / 0.5$ \\
C & $80 / 20 / 30$ & $1 / 1.5$ \\
D & $80 / 20 / 40$ & $1 / 2$ \\
\hline
\end{tabular}


MAAH. Both reactions are performed simultaneously in 2 different pots and allowed to run for $45 \mathrm{~min}$. Here, silanol groups are formed with a minimum of siloxane groups and the number of reactive alkoxide groups on the zirconium precursor are reduced to minimise its reactivity towards water in the following steps of the process. 2) Addition of the hydrolysed MAPTMS to the ZC. This enables an indirect hydrolysis of the ZC. Indeed, as previously demonstrated [23], the hydroxyl groups located on the silicon atom are transferred to the zirconium atom, along with the formation of siloxane and Si-O-Zr bonds. (3) Hydrolysis of the mixture with deionised water is performed to pursue the formation of the inorganic backbone.

\subsection{Preparation of Sol-Gel Coatings}

AA2024-T3 aluminium panels $(150 \mathrm{~mm} \times 100 \mathrm{~mm})$ were sourced from Amari (Irl.) Ltd., Clondalkin, Ireland. The panels were first degreased with isopropanol and subsequently etched using a hydrofluoric acid aqueous solution (Novaclean 104, Henkel, Irl.) and a sulphuric acid aqueous solution (Novox 302, Henkel, Irl.). This final acid rinsing step enabled the surface activation by the creation of hydroxyl groups. The sols were filtered using a 0.45 micron syringe filter and deposited employing a spin-coater at $1000 \mathrm{rpm}$ under an alcohol saturated environment. The coatings fabrications were performed in a cleanroom environment to avoid particles contamination. The fabricated coatings showed thicknesses of 4.5 to $5 \mu \mathrm{m}$, as determined using a non-ferrous thickness probe (Elcometer 256). The coatings were then cured for one hour at $120^{\circ} \mathrm{C}$ to enable full stabilisation. The curing temperature of $120^{\circ} \mathrm{C}$ was chosen to ensure that the effect of the condensation was focused solely on condensation resulting from chemical and not thermal means, e.g. as a result of heat curing. This process facilitates the fabrication of highly homogeneous and residue free coatings, a critical point for the accurate correlation of the coatings formulations to their structures and anticorrosion properties.

\subsection{Characterisation Techniques}

Sol-gel particle sizes were determined using the dynamic light scattering (DLS) technique (a Malvern Nano-ZS instrument). The technique is a well-established optical method used to study dynamic processes of liquids and solids [24]. The experiment was conducted at ambient temperature.

Fourier Transform InfraRed (FTIR) spectra were recorded in the $600-4000$ $\mathrm{cm}^{-1}$ spectral range employing a Spotlight 400 FTIR Imaging System operating in the ATR mode. Here, FTIR spectroscopy is used to identify the evolution of the inorganic networks (silicate and zirconium oxides) as a function of the chelating agent content.

Dynamic Scanning Calorimetry (DSC) was used to identify the thermal behaviour of the sol-gels, including their structural evolution and glass transition temperature (Tg). DSC measurements were carried out using a Shimadzu DSC 
60 QC instrument under an air atmosphere at a heating rate of $5^{\circ} \mathrm{C} / \mathrm{min}$ between $25^{\circ} \mathrm{C}$ and $225^{\circ} \mathrm{C}$. Samples were prepared by dropping $10 \mu \mathrm{l}$ of the liquid sol-gels into an aluminium sample pan.

Scanning Electron Microscopy (SEM) images were recorded employing a $\mathrm{Hi}$ tachi SU-70 scanning electron microscope using an accelerating voltage of 1.5 $\mathrm{keV}$ and $10 \mathrm{keV}$ for SEM imaging and $10 \mathrm{keV}$ for Energy Dispersive Spectroscope (EDS) analyses. Prior to analysis, the samples were mounted by the mixture of EpoFix resin and EpoFix hardener $(25: 3 \mathrm{w} / \mathrm{w})$. The mounted samples were polished using different grades of silicon carbide papers, ranging from coarse to fine. The polishing was carried out using a diamond suspension with particles sizes of 9, 3 and $1 \mu \mathrm{m}$. The polishing process was carried out using a Motopol ${ }^{\mathrm{rm}}$ 2000 grinder/polisher. The polished samples were coated with approximately 1 $\mathrm{nm}$ and $7 \mathrm{~nm}$ of platinum/palladium coating, for cross-section and top-view imaging, respectively, using a Cressington 208HR sputter coater.

Electrochemical impedance spectroscopy (EIS) testing was carried out with a Gamry potentiostat/galvanostat controlled by a Gamry framework software. The employed electrolyte solution was a $3.5 \% \mathrm{NaCl}$ solution, the exposure area of the samples was $1.76 \mathrm{~cm}^{2}$ and a three-electrode standard corrosion cell was employed to record the electrochemical behaviour of the coatings. All measurements were made at the open circuit potential (OCP, Eoc) with an applied 10 $\mathrm{mV}$ sinusoidal perturbation in the frequency range $10^{5}-10^{-2} \mathrm{~Hz}$ (logarithmic scale) in alternating-current (AC). All experiments were reiterated at least three times to check reproducibility.

\section{Results and Discussion}

\subsection{Particle Size Analysis}

The particle sizes of all prepared materials were investigated by DLS to identify the effect of the formulation on the condensation reactions and therefore provide indications on the reactivity of the materials. The Full-Width Half Maximum (FWHM) values associated with the various particle size distribution bands recorded by DLS offer further useful information on the homogeneity of the materials. As it is well known that sol-gel materials are systems which undergo continuous condensation reactions, DLS analyses are critical to identify the stability and lifetime of the sol-gel materials and, therefore, their potential for long-term use. Particle sizes for all materials have been recorded after 1 and 2 days of ageing and are represented in Figure 1. As all coatings were prepared after 1 day of ageing, it was useful to also get a picture of the particle size of all material systems on day 1 to identify if this parameter can be correlated to the subsequent structural properties and the coatings' anticorrosion properties. It can be observed that after one day of ageing material A exhibits a single band centred at $5.6 \mathrm{~nm}$ whereas the other three materials show a band located between 3.6 and $4.2 \mathrm{~nm}$. The samples' particle size distribution appears to be broadly stable, with peak values for materials A-D centred at $3.6 \mathrm{~nm}$ on day 2 . 


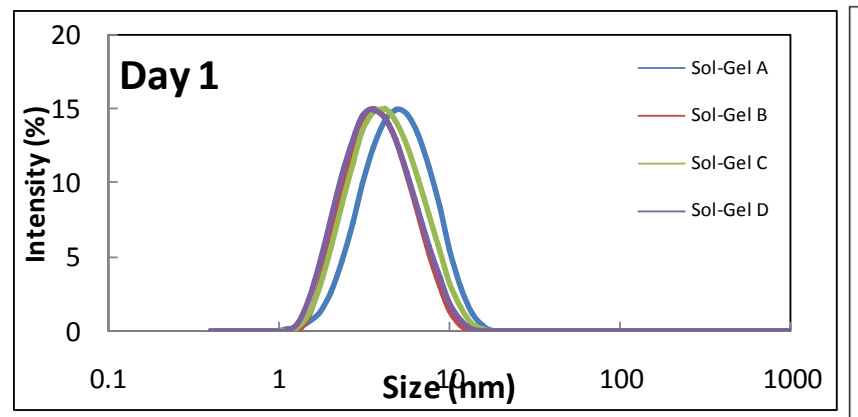

(a)

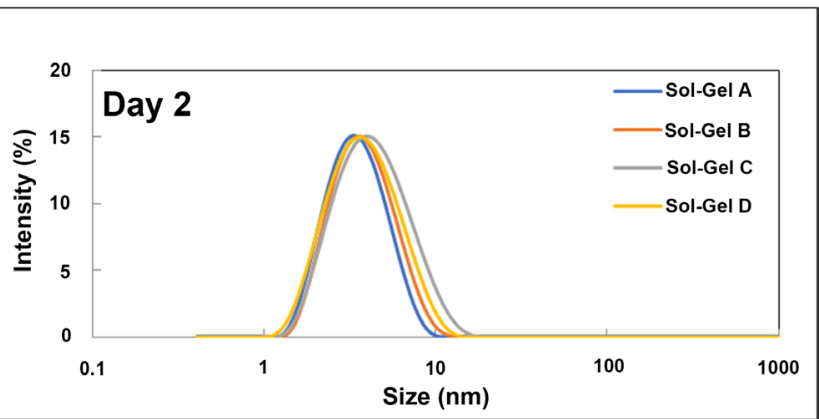

(b)

Figure 1. DLS spectra for sol-gel A to D.

The differences in terms of particle size observed after one day of reaction are primarily due to the minimum degree of chelation for material $\mathrm{A}$. The fact that the particle size is seen to slightly decrease after 2 days of ageing would indicate that the particles recorded after 1 day of reaction are probably composed of agglomerated particles of different sizes that separate as the ageing increase to build particles of more homogeneous sizes. As this phenomenon is only observed for material A, one can suppose that since in this material the zirconium atom is the least chelated, its capability to attract hydrophilic species such as the silanol groups located at the surface of the nanoparticle enables to form physical interactions such as hydrogen bonds, essentially because of the strong hydrophilic character, a property well-known for transition metal alkoxides, as previously demonstrated [25] [26] [27].

In order to better appreciate the possible effect of the formulation on the structure and homogeneity of the hybrid sol-gel nanoparticles, the FWHM of all spectra has been measured and plotted in Figure 2. One can observe that the material exhibiting the highest heterogeneity in terms of particle sizes is material A after 1 day of reaction, with a FWHM of $6.4 \mathrm{~nm}$, while the three other materials range within the error bars at values close to $5 \mathrm{~nm}$. As all materials exhibit particles size in the same order (typically less than $10 \mathrm{~nm}$ ), it is unlikely that the particle size influence the structure and anticorrosion properties of the materials. Therefore, any differences in terms of structure and corrosion behaviour will be ascribed to materials formulation and not to particles sizes.

\subsection{FTIR Analysis}

Figure 3(a) shows the FTIR spectra of all prepared coatings. All absorption bands were ascribed based on results reported previously on closely related materials [28] [29] [30] [31]. These spectra show the presence of the same chemical vibrations due to the employment of the same precursors and material preparation conditions; the difference being essentially in the concentration of the chelating agent. The broad band located in the range $800-1200 \mathrm{~cm}^{-1}$ is characteristic of the silicon-based groups resulting mainly from the superimposition of the silanol $\left(\mathrm{Si}-\mathrm{OH}, 840 \mathrm{~cm}^{-1}\right)$ stretches, C-Si-OCH ${ }_{3}$ stretches $\left(890 \mathrm{~cm}^{-1}\right)$, Si-O-Si 


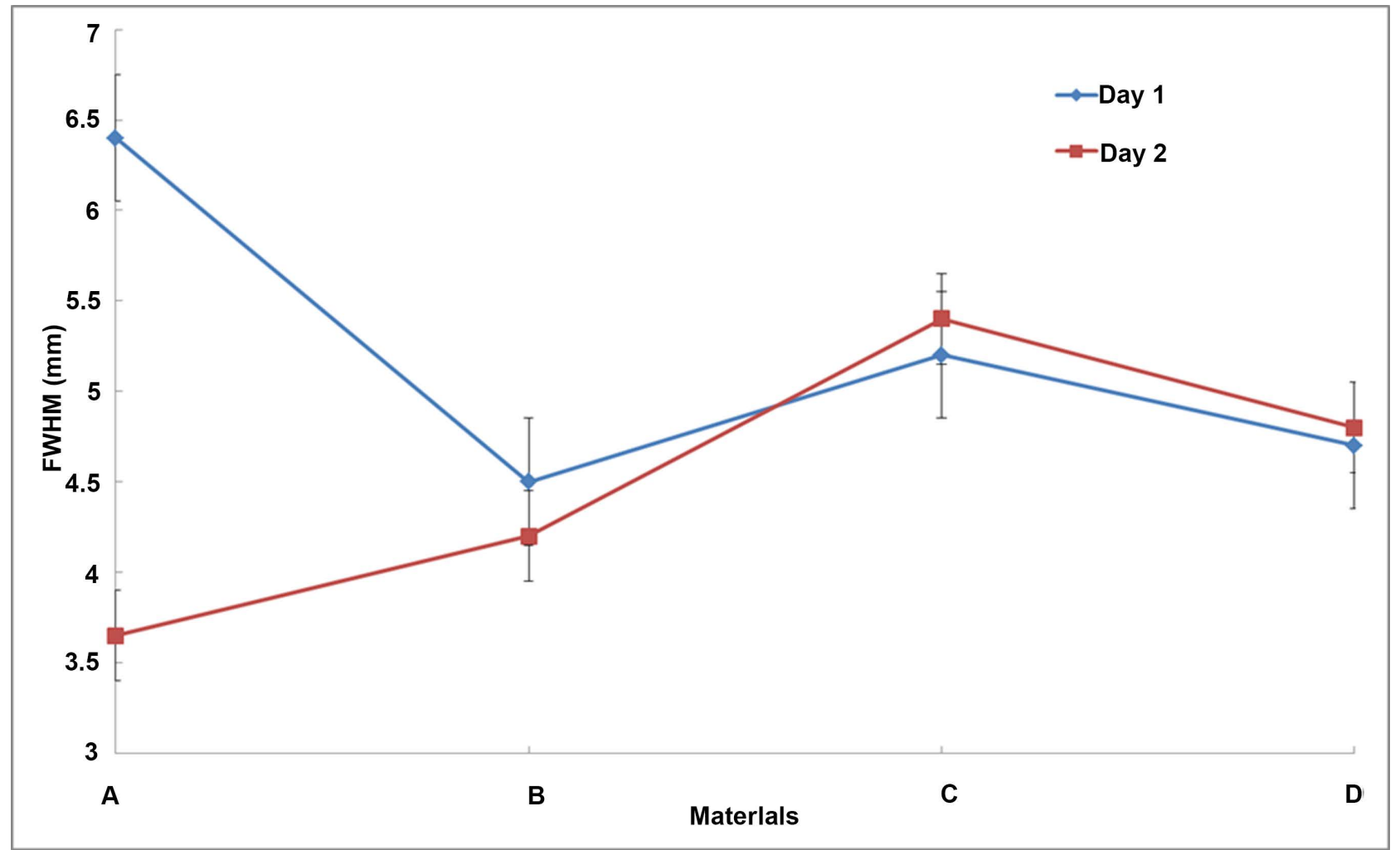

Figure 2. Representation of the FWHM for all materials after 1 and 2 days of ageing.

(820 and $1010-1150 \mathrm{~cm}^{-1}$ ) and Si-O-Zr vibrations $\left(940 \mathrm{~cm}^{-1}\right)$. The band observed at $1170 \mathrm{~cm}^{-1}$ symbolises the stretching of the Si-O-C contained in the methoxysilane groups of the MAPTMS. The $\mathrm{Zr}-\mathrm{OH}$ and $\mathrm{Zr}-\mathrm{O}-\mathrm{C}$ bonds composing the zirconium complex are located in the region $1300-1650 \mathrm{~cm}^{-1}$. The Zr-MAAH complex possesses two peaks around $1635 \mathrm{~cm}^{-1}$ and $1533 \mathrm{~cm}^{-1}$, which are ascribable to the symmetric $\left(v_{\mathrm{s}}\right)$ and asymmetric stretching $\left(v_{\mathrm{as}}\right)$ vibrations of the carboxylic group $\left(\mathrm{COO}^{-}\right)$, respectively [32]. With a $\Delta \mathrm{v}\left(\mathrm{COO}^{-}\right)$value of $102 \mathrm{~cm}^{-1}$, the chelate can be said to be bidentate. The bands located at 1730, 2800,3000 and $3200 \mathrm{~cm}^{-1}$ are due to the $\mathrm{C}-\mathrm{O}$ (stretching), $\mathrm{C}-\mathrm{H}$ (stretching) and residual $\mathrm{Si}-\mathrm{OH}$ and $\mathrm{Zr}-\mathrm{OH}$ groups (stretching), respectively.

To identify more precisely the effect of the chelating agent concentration on the possible reactivity and condensation of the materials, one needs to focus on the characteristic vibration bands of the inorganic backbone; namely the silicon and zirconium oxide related moieties. As shown in Figure 3(b), the typical vibrations of the siloxane bands located at $820 \mathrm{~cm}^{-1}$ and in the range $1010-1040$ $\mathrm{cm}^{-1}$ can be observed in all samples demonstrating the occurrence of the sol-gel condensation reactions of the organosilane. However, it can be observed that the relative contribution of the band located at $940 \mathrm{~cm}^{-1}$ against the large band located between $1010-1150 \mathrm{~cm}^{-1}$ is progressively increasing as the concentration of the chelating agent decreases, suggesting that the formation of Si-O-Zr bonds are favoured by low chelation degrees. In addition, it can be observed that within the $1010-1150 \mathrm{~cm}^{-1}$, one can notice that the high energy silicate vibrations, 


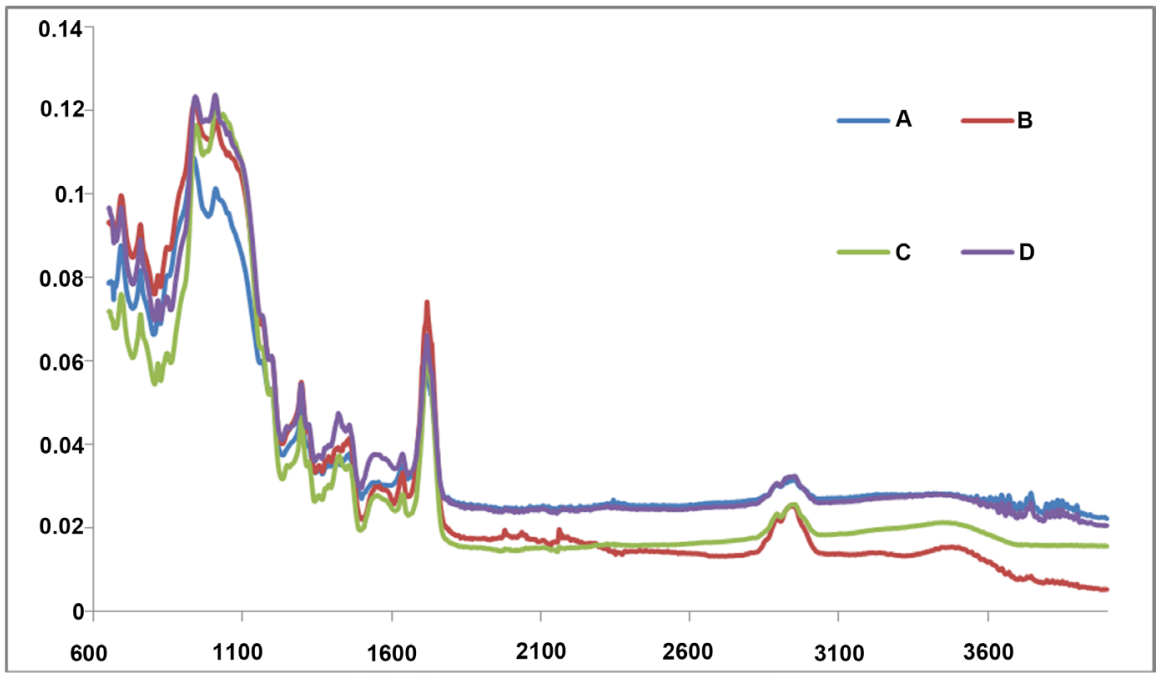

(a)

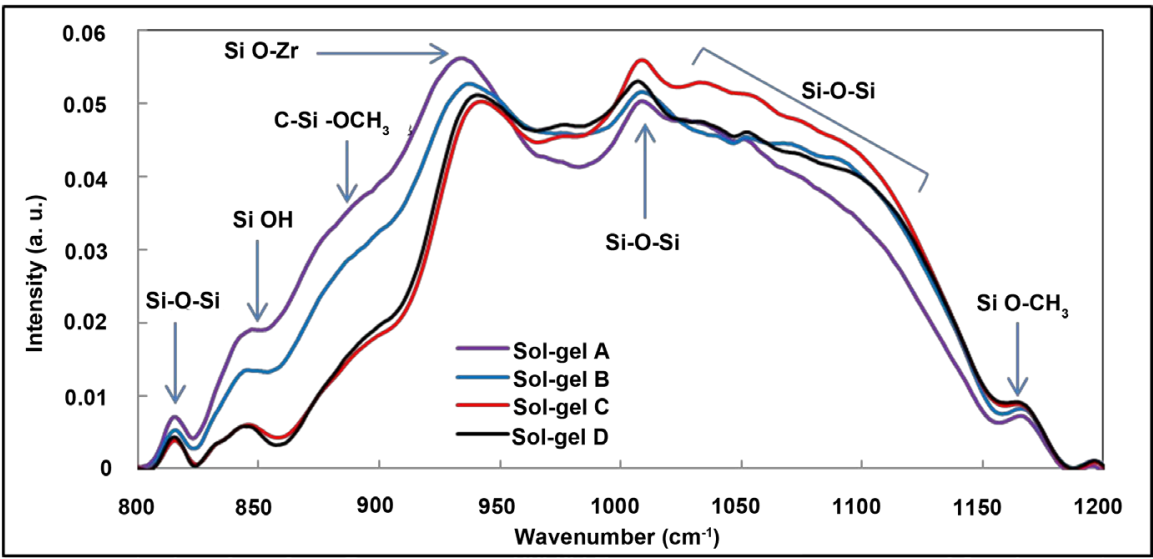

(b)

Figure 3. FTIR spectrum for coatings A to D (a) in the range $600-4000 \mathrm{~cm}^{-1}$ and (b) in the range 800 and $1300 \mathrm{~cm}^{-1}$.

composed by the superimposition of 3 to 4 bands in the region $1025-1150 \mathrm{~cm}^{-1}$, are increasing in comparison to the lower energy siloxane groups the band of which is centred at $1010 \mathrm{~cm}^{-1}$. This signifies that the increase of chelation degree favours the formation of siloxane bonds, probably siloxane bonds with higher degree of connectivity on the same silicon atom, via the occurrence of polycondensation reactions of the silanol groups together $\left(\mathrm{Si}-\mathrm{OH}+\mathrm{Si}-\mathrm{OH} \mathrm{Si}-\mathrm{O}-\mathrm{Si}+\mathrm{H}_{2} \mathrm{O}\right)$ or with methoxysilane groups $\left(\mathrm{Si}-\mathrm{OH}+\mathrm{Si}-\mathrm{OCH}_{3} \mathrm{Si}-\mathrm{O}-\mathrm{Si}+\mathrm{CH}_{3} \mathrm{OH}\right)$ into siloxane species. This can primarily be explained by the presence of the chelating agent around the zirconium atom limiting the condensation reactions with the silicate network.

Fundamentally, these results prove that a competition between the condensation of the silicate ( $\mathrm{Si}-\mathrm{O}-\mathrm{Si}$ ) and silicon-zirconium oxides ( $\mathrm{Si}-\mathrm{O}-\mathrm{Zr}$ ) species is taking place within these materials, and that the concentration of the chelating agent can be tailored to control these reactions. This result is valuable in the chemistry of sol-gel materials as to our knowledge this fundamental aspect has 
not been shown previously in the literature. These results are however insufficient to conclude on the resulting morphology of the series of materials developed herein.

\subsection{Thermal Analysis}

DSC analyses were performed on liquid sol-gel materials between room temperature $\left(25^{\circ} \mathrm{C}\right)$ and $275^{\circ} \mathrm{C}$, although the working temperature for a typical hybrid coating would be likely to be below $150^{\circ} \mathrm{C}$. Figure 4 shows the DSC spectra recorded for all prepared samples. Three different thermal zones can be identified namely, below $100^{\circ} \mathrm{C}$, between $170^{\circ} \mathrm{C}$ and $185^{\circ} \mathrm{C}$ and above $200^{\circ} \mathrm{C}$, where typically the evaporation of the solvents, condensation reactions and glass transition take place, respectively. For all samples, a large endothermic band can be observed in the range $20^{\circ} \mathrm{C}-60^{\circ} \mathrm{C}$, suggesting the evaporation of the volatile solvents formed during the sol-gel synthesis or present in the precursors. The first exothermic band observed in the range $165^{\circ} \mathrm{C}-200^{\circ} \mathrm{C}$ symbolises the full condensation of the materials. This band is located at $172^{\circ} \mathrm{C}, 176^{\circ} \mathrm{C}, 180^{\circ} \mathrm{C}$ and $181^{\circ} \mathrm{C}$ for materials $\mathrm{A}$ to $\mathrm{D}$, respectively. This progressive shift towards higher temperature by a step of 3 degrees as the degree of chelation increases demonstrates that the full condensation of the materials relies on the environment of the zirconium.

By correlating these results to the FTIR results, where it was found that the increase of chelation degree decreases the condensation of the formation of siloxane bonds ( $\mathrm{Si}-\mathrm{O}-\mathrm{Si}$ ) for the benefit of the formation of silicon zirconium oxide groups ( $\mathrm{Si}-\mathrm{O}-\mathrm{Zr}$ ), it can be proposed that the increase of chelating agent concentration reduces the solidification ability of the hybrid materials. This result is further confirmed by the crystallisation temperature of the materials.

Indeed, for materials $\mathrm{A}$ and $\mathrm{B}$, this band is observed at $233^{\circ} \mathrm{C}$ and $265^{\circ} \mathrm{C}$, respectively. However, this band is not observed for materials $\mathrm{C}$ and $\mathrm{D}$ within the

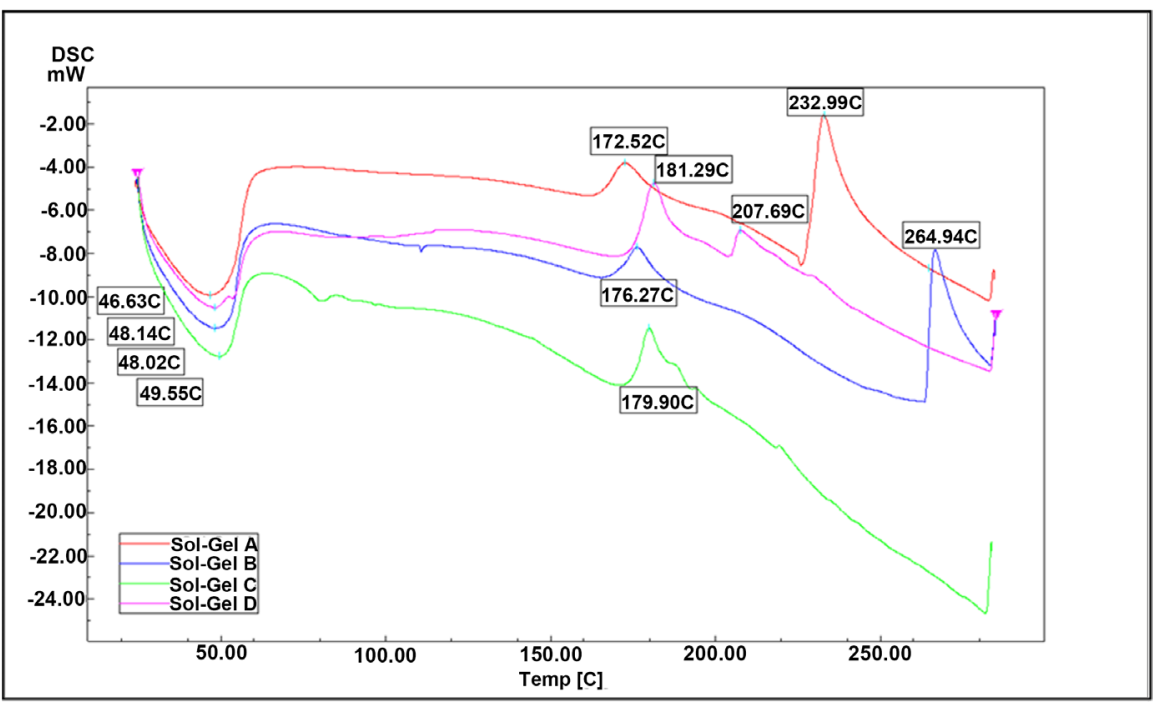

Figure 4. DSC analyses for materials A to D. 
characterised temperature domain. The fact that this phenomenon takes place at the lowest temperatures for material A demonstrates that this material exhibits the highest condensation capability of all materials. Also, as this band is not seen for materials $\mathrm{C}$ and $\mathrm{D}$, this suggests a definite lower capability for condensation. Moreover, the observation of shouldering bands for material $\mathrm{C}$ and $\mathrm{D}$ at around $190^{\circ} \mathrm{C}$ and $208^{\circ} \mathrm{C}$, respectively, demonstrates that the solidification temperature, observed as a single band for materials $\mathrm{A}$ and $\mathrm{B}$ (at $172^{\circ} \mathrm{C}$ and $176^{\circ} \mathrm{C}$, respectively) reveals a higher degree of heterogeneity for materials $\mathrm{C}$ and $\mathrm{D}$. In summary, the thermal analyses are in agreement with the FTIR results as they demonstrate an increase of the condensation capability as the degree of chelation decreases.

\subsection{SEM/EDX Analyses}

Figure 5 represents a typical SEM image of a coating fabricated with these series of materials (material A in this case) coated onto AA2024-T3 alloy. It can be seen that the coating thicknesses were comprised between 4.5 and 5 microns (Figure 5(a)) and the surfaces of the coatings (Figure 5(b) and Figure 5(c)) were smooth and uniform unlike the blank aluminium alloy. Figure 6 shows the elemental analysis of the coating. This technique clearly identifies the interface between the coating and the substrate, as within the coating silicon, zirconium and oxygen can be detected, whereas aluminium is found in the bottom region of the spectrum only.

\subsection{Electrochemical Impedance Spectroscopy (EIS)}

EIS consists of applying an $\mathrm{AC}$ voltage at the open circuit potential (OCP), with a sinusoidal amplitude of varying frequency across a coating in contact with an aggressive electrolyte. The coatings' resistance to the AC signal, or impedance, varies according to the applied frequency and is graphically represented on a Bode frequency plot. The phase angle associated with the impedance gives valuable information on the film properties such as barrier performance and interfacial activity. This activity is often seen as a build-up of an oxide material, usually

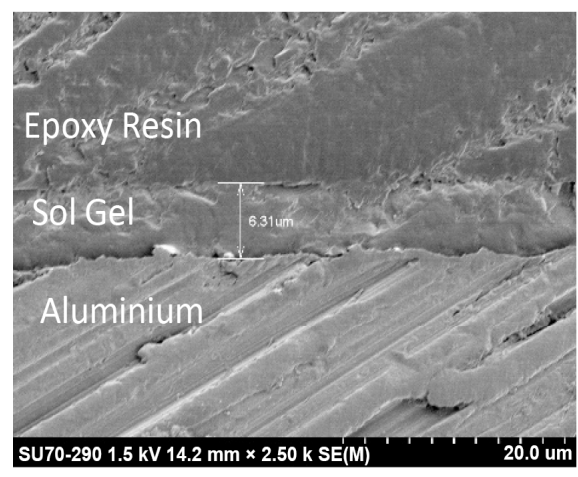

(a)

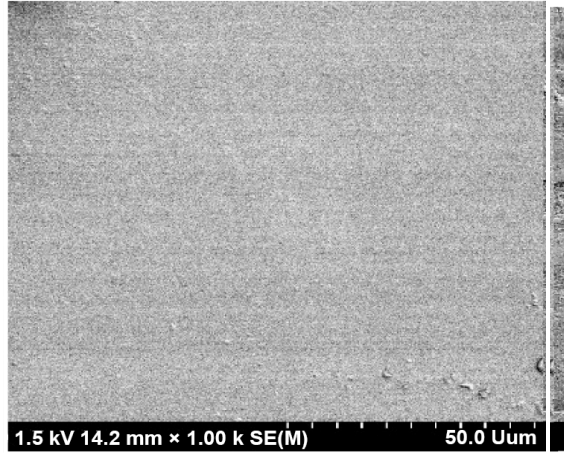

(b)

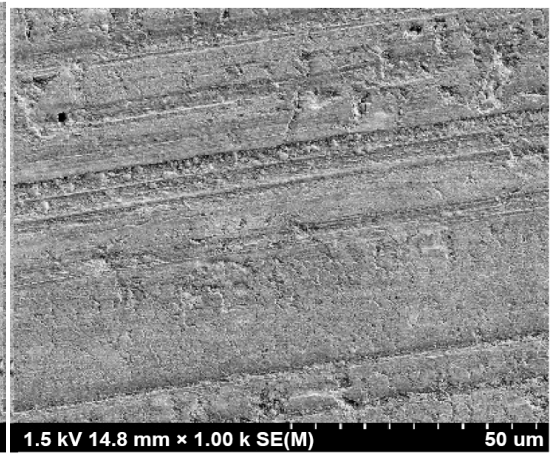

(c)

Figure 5. SEM images of cross-section (a) and top view (b) of sol-gel A deposited on an AA2024-T3 aluminium substrate, and (c) an SEM image of the bare AA2024-T3 surface. 


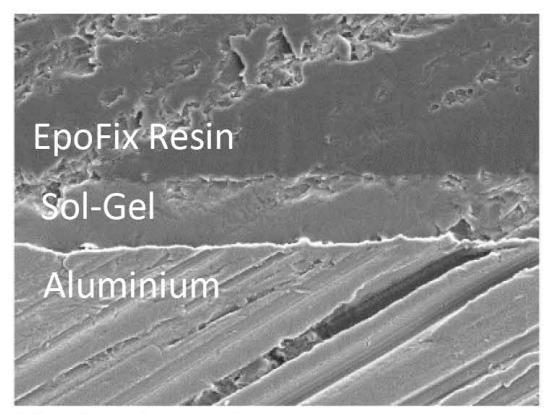

Electron Image 1

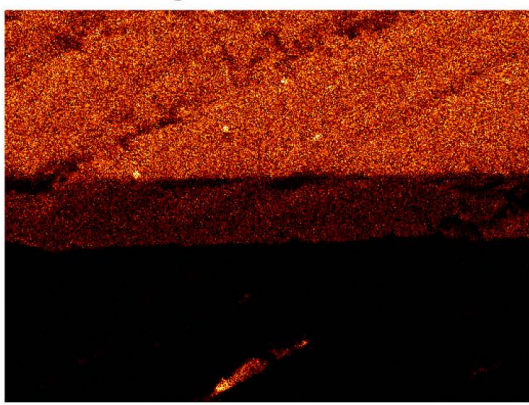

C Ka 1_2

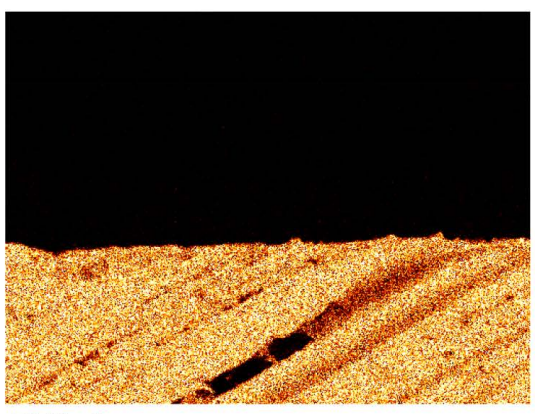

Al Ka 1

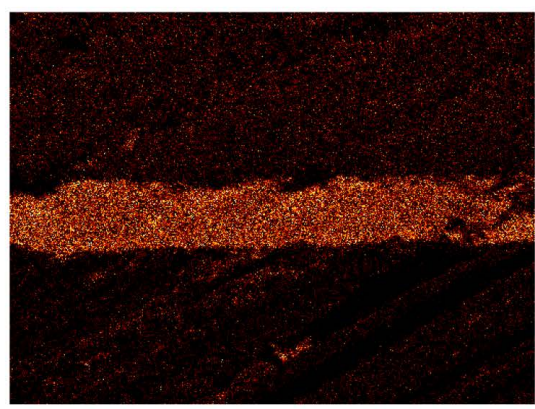

O Ka 1

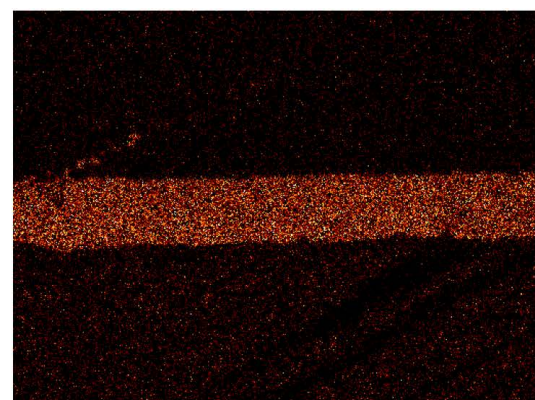

Si Ka 1

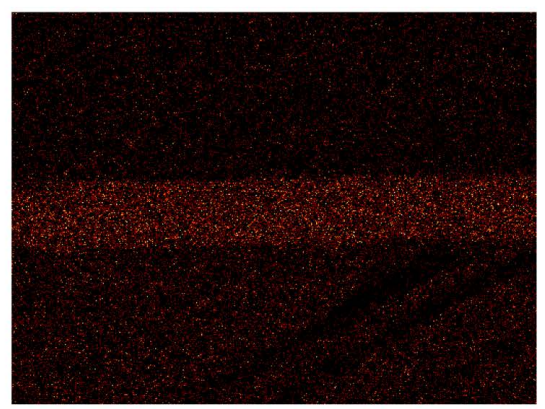

Zr La 1

Figure 6. SEM micrograph and element map of sol-gel material A coated onto AA2024-T3, encased in EpoFix resin.

corrosion product which may present charge transfer at the metal surface thus increasing the effective interfacial capacitance. The process can be modelled as an equivalent circuit as explained elsewhere [33].

The Bode plot for all coatings after exposure to Harrison's solution electrolyte after 1,24 and $48 \mathrm{~h}$ are represented in Figure 7. The behaviour of the blank substrate after 1 hour of exposure is also represented. After 1 hour of exposure, coatings A and B show a single time constant at a frequency of $1000 \mathrm{~Hz}$, while coatings $\mathrm{C}$ shows an additional time constant around $10 \mathrm{~Hz}$. Phase angle recorded for coating $\mathrm{D}$ is observed to be fluctuating in the $0.1-100 \mathrm{~Hz}$ frequency region, with three-time constants positioned at $0.4,10$ and $1000 \mathrm{~Hz}$, suggesting this coating would be the least stable one of the series after 1 hour of exposure. After $24 \mathrm{~h}$ of exposure, coating A still shows as single time constants positioned at high frequency, while two additional time constants appear for coating $B$ at 0.3 and $40 \mathrm{~Hz}$. Coatings $\mathrm{C}$ and $\mathrm{D}$ also show a three-time constant behaviour positioned around 0.4, 3 and over $10000 \mathrm{~Hz}$. After $48 \mathrm{~h}$ of exposure, coating A still exhibit a typical single time constant behaviour at high frequency. Three-time constants are still observed for material B with an observed shift towards the higher frequencies observed for the middle and high-frequency time constants. Interestingly, the three-time constants observed for coatings $\mathrm{C}$ and $\mathrm{D}$ after $24 \mathrm{~h}$ of exposure have turned into a two-time constant behaviour after $48 \mathrm{~h}$ of exposure. Unlike coatings $\mathrm{B}, \mathrm{C}$ and $\mathrm{D}$, the invariance of the time constants behaviour for coating A traduces a highly condensed coating with a minimum effect of the electrolyte on the surface properties of the metal. The decrease in the number of time constants for material C and D from 24 to $48 \mathrm{~h}$ of exposure translates interaction between the corrosive electrolyte and the metal surface, resulting very 

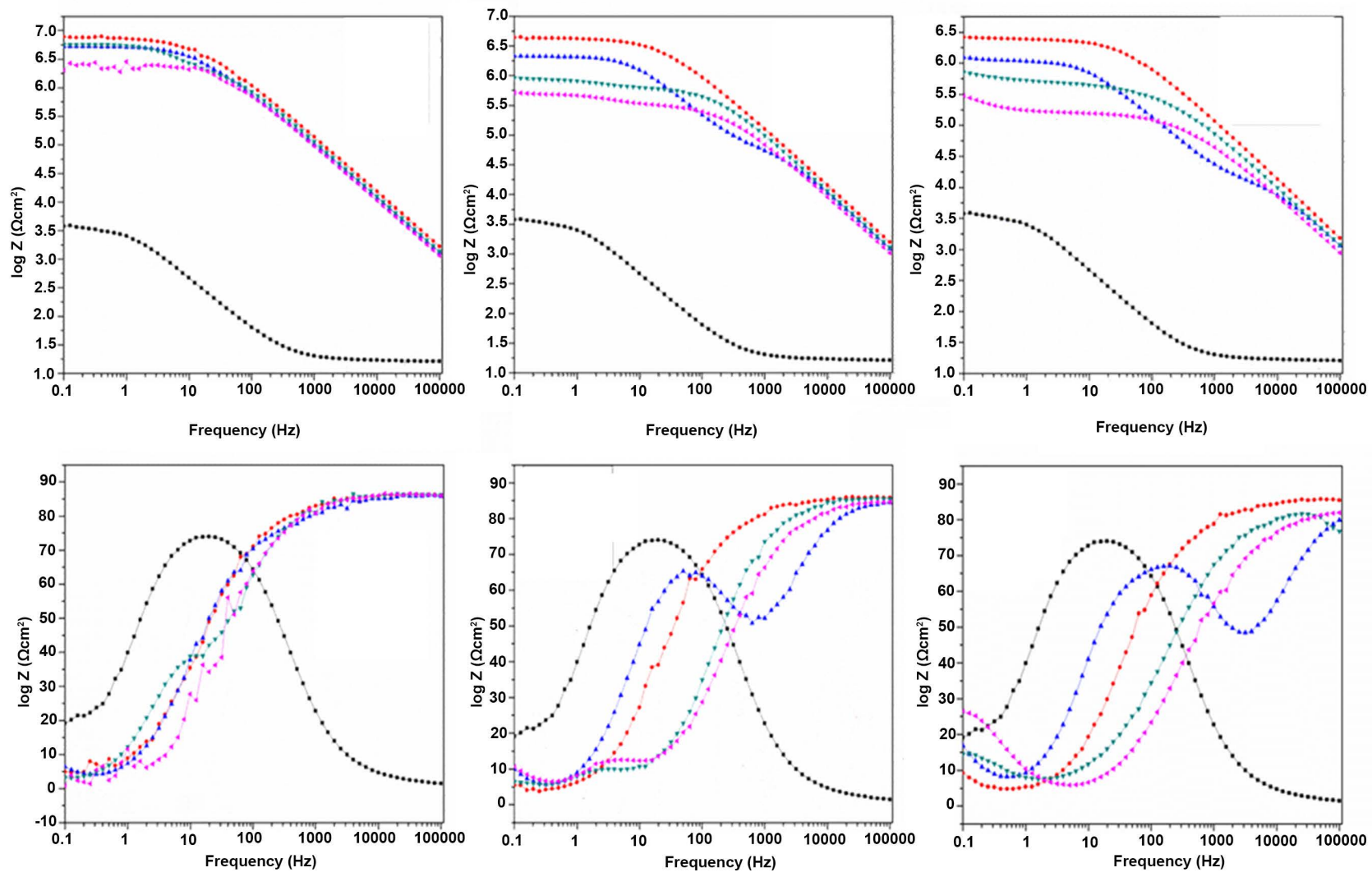

Figure 7. Bode plots of coatings A (red), B (blue), C (green) and D (purple) after 1, 24 and 48 h (left to right) of exposure to Harrison's solution.

likely in the formation of an upper oxide layer that provides greater stability to the metal. Therefore, these coatings must exhibit a similar degree of porosity to enable the penetration of the corrosive liquid towards the metallic substrate. As the number of time constants does not change from 24 to $48 \mathrm{~h}$ of exposure for coating $B$, it is very likely that this coating exhibits intermediate properties in terms of porosities to coating $\mathrm{A}$ and the two coatings $\mathrm{C}$ and $\mathrm{D}$.

In order to better appreciate the protection behaviour of the prepared coatings, impedance values recorded at the lowest frequency as function of exposure time has been represented in Figure 8. It can be seen that after $1 \mathrm{~h}$ of exposure, the highest impedance value measured for coating $A$ at $10^{6.8} \Omega / \mathrm{cm}^{2}$. Coatings $B$ and $C$ are showing similar impedance values around $10^{6.7} \Omega / \mathrm{cm}^{2}$, while coating D exhibits the lowest impedance value at $10^{6.25} \Omega / \mathrm{cm}^{2}$. After $24 \mathrm{~h}$ of exposure to the Harrison's solution, the impedance values for all coatings are undergoing a decrease, with recorded values of $10^{6.6}, 10^{6.2}, 10^{6}$ and $10^{5.7} \Omega / \mathrm{cm}^{2}$ for coatings A to $\mathrm{D}$, respectively. It is worthy to note that coating $\mathrm{C}$ exhibits the highest relative impedance value decrease of $10^{0.8} \Omega / \mathrm{cm}^{2}$, while coating A showed the minimum decrease of $10^{0.2} \Omega / \mathrm{cm}^{2}$. Coatings B and D showed a similar trend with a decrease of $10^{0.5} \Omega / \mathrm{cm}^{2}$. After $48 \mathrm{~h}$ of exposure, the decrease continues to take place as measured values are of $10^{6.4}, 10^{6.1}, 10^{5.8}$ and $10^{5.5} \Omega / \mathrm{cm}^{2}$, for coatings $A$ to $\mathrm{D}$, respectively. After $48 \mathrm{~h}$ of exposure, the same trend of impedance values is 


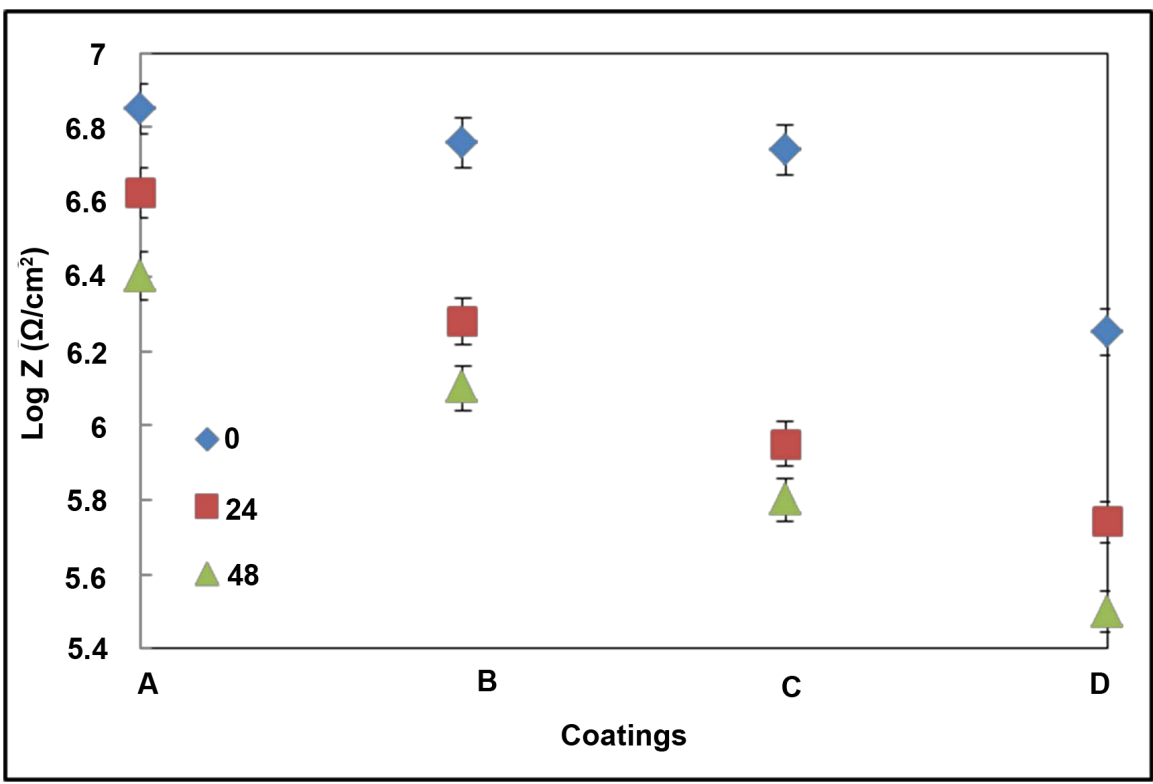

Figure 8. Impedance values for coatings $A$ to $D$ at a frequency of $0.1 \mathrm{~Hz}$, for exposure times of 1,24 and 48 h to Harrison's solution.

observed with coating A still exhibiting the highest resistance with a recorded impedance value of $10^{6.4} \Omega / \mathrm{cm}^{2}$. These results further confirm that the most resistant coating of the series developed here is coating A, followed by coatings B, $\mathrm{C}$ and $\mathrm{D}$. This behaviour can primarily be explained by the condensation capabilities of the coatings that follow the same trend, as demonstrated above by the FTIR results.

\section{Conclusion}

This work aimed at identifying the effect of the chelating agent on the structure and anticorrosion properties of hybrid sol-gel materials composed of both silicon and zirconium alkoxides. It is shown that the degree of chelation of the transition metal has a direct impact on the nature of its connectivity to the silicate network with a direct consequence on the densification process of the nanomaterials. Indeed, the formation of covalent $\mathrm{Si}-\mathrm{O}-\mathrm{Zr}$ bonds is found to be favoured by the decrease of chelation, essentially due to the increase of reactive zirconium groups. This clearly translates the formation of coatings with higher densities. In parallel, the anticorrosion performances of the coatings were found to significantly increase as the chelation degree decreases. Interestingly, of the series of materials investigated here, the least chelated material exhibited the minimum change in the impedance value over time, with a value of $10^{6.4} \Omega / \mathrm{cm}^{2}$ recorded after $48 \mathrm{~h}$ of exposure to a Harrison's solution. These results suggest that further decrease of the chelation degree may enable increase of the anticorrosion barrier properties of the sol-gel coatings. In addition, further studies are required to better correlate the structure and morphology of hybrid sol-gel coatings to their anticorrosion performances. These will include the investigation of other processing parameters such as $\mathrm{pH}$ and the hydrolysis degree, as 
well as employing other structural and morphological characterisation techniques, such as gas adsorption-desorption analysis and ${ }^{29} \mathrm{Si}$-NMR on the solid phase of the materials. These are critical steps for the future design of innovative, non-toxic and environmentally friendly coatings for the protection of aluminium alloys and other metals.

\section{References}

[1] Official Journal of the European Union (2011) Commission Directive 2011/37/EU. Official Journal of the European Union, Brussels, 269.

[2] EPA Federal Register (1995) National Emission Standards for Hazardous Air Pollutants for Source Categories: Aerospace Manufacturing and Rework Facilities. National Archives and Records Administration, Vol 60, Article ID: 45947.

[3] Pommiers, S., Frayret, J., Castetbon, A., Potin-Gautier, M. (2014) Alternative Conversion Coatings to Chromate for the Protection of Magnesium Alloys. Corrosion Science, 84, 135-146. https://doi.org/10.1016/j.corsci.2014.03.021

[4] Hornberger, H., Virtanen, S. and Boccaccini, A.R. (2012) Biomedical Coatings on Magnesium Alloys-A Review. Acta Biomaterialia, 8, 2442-2455. https://doi.org/10.1016/j.actbio.2012.04.012

[5] Amini, R. and Sarabi, A.A. (2011) The Corrosion Properties of Phosphate Coating on AZ31 Magnesium Alloy: The Effect of Sodium Dodecyl Sulfate (SDS) as an Eco-Friendly Accelerating Agent. Applied Surface Science, 257, 7134-7139. https://doi.org/10.1016/j.apsusc.2011.03.072

[6] Rita, B., Figueira, I.R., Fontinha, C.J., Silva, R. and Pereira, E.V. (2016) Hybrid Sol-Gel Coatings: Smart and Green Materials for Corrosion Mitigation. Coatings, 6, 12 .

[7] Amiri, S. and Rahimi, A. (2016) Hybrid Nanocomposite Coating by sol-gel Method: A Review. Iranian Polymer Journal, 25, 559-577. https://doi.org/10.1007/s13726-016-0440-x

[8] Marques, M.E., Alexandra, A., Mansur, P. and Mansur, H.S. (2013) Chemical Functionalization of Surfaces for Building Three-Dimensional Engineered Biosensors. Applied Surface Science, 275, 347-360. https://doi.org/10.1016/j.apsusc.2012.12.099

[9] Su, H.-Y., Chen, P.-L. and Lina, C.-S. (2016) Sol-gel Coatings Doped with Organosilane and Cerium to Improve the Properties of Hot-Dip Galvanized Steel. Corrosion Science, 102, 63-71. https://doi.org/10.1016/j.corsci.2015.09.019

[10] Chichkov, B.N. and Farsari, M. (2009) Materials Processing: Two-Photon Fabrication. Nature Photonics, 3, 450-452.

[11] Oubaha, M., Gorin, A., McDonagh, C., Duffy, B. and Copperwhite, R. (2015) Development of a Multianalyte Optical Sol-Gel Biosensor for Medical Diagnostic. Sensors and Actuators B, 221, 96-103. https://doi.org/10.1016/j.snb.2015.06.012

[12] Fedel, M., Callone, E., Fabbian, M., Deflorian, F. and Dirè, S. (2017) Influence of $\mathrm{Ce}^{3+}$ Doping on Molecular Organization of Si-Based Organic/Inorganic Sol-Gel Layers for Corrosion Protection. Applied Surface Science, 414, 82-91. https://doi.org/10.1016/j.apsusc.2017.04.071

[13] Moutarlier, V., Neveu, B. and Gigandet, M.P. (2008) Evolution of Corrosion Protection for Sol-Gel Coatings Doped with Inorganic Inhibitors. Surface and Coatings Technology, 202, 2052-2058. https://doi.org/10.1016/j.surfcoat.2007.08.040

[14] Upadhyay, V., Bergseth, Z., Kelly, B. and Battocchi, D. (2017) Silica-Based Sol-Gel 
Coating on Magnesium Alloy with Green Inhibitors. Coatings, 7, 86. https://doi.org/10.3390/coatings7070086

[15] Colreavy, J., Duffy, B., Varma, P.C.R., Hayden, H. and Oubaha, M. (2009) Sol-Gel Coating Compositions and Their Process of Preparation. EP 2220176 A2.

[16] Lebeau, B. and Innocenzi, P. (2011) Hybrid Materials for Optics and Photonics. Chemical Society Reviews, 40, 886-906. https://doi.org/10.1039/c0cs00106f

[17] Ferreira, R.A.S., André, P.S. and Carlos, L.D. (2010) Organic-Inorganic Hybrid Materials towards Passive and Active Architectures for the Next Generation of Optical Networks. Optical Materials, 32, 1397-1409. https://doi.org/10.1016/j.optmat.2010.06.019

[18] Elmaghrum, S., Gorin, A., Kribich, R.K., Corcoran, B., Copperwhite, R., McDonagh, C. and Oubaha, M. (2013) Development of a Sol-Gel Photonic Sensor Platform for the Detection of Biofilm Formation. Sensors and Actuators B, 177, 357-363. https://doi.org/10.1016/j.snb.2012.10.100

[19] Oubaha, M., Kavanagh, A., Gorin, A., Bickauskaite, G., Byrne, R., Farsari, M., Winfield, R., Diamond, D., McDonagh, C. and Copperwhite, R. (2012) Graphene-Doped Photo-Patternable Ionogels: Tuning of Conductivity and Mechanical Stability of 3D Microstructures. Journal of Materials Chemistry, 22, 10552-10559. https://doi.org/10.1039/c2jm30512g

[20] Cullen, M., Morshed, M., O’Sullivan, M., MacHugh, E., Duffy, B. and Oubaha, M. (2017) Correlation between the Structure and the Anticorrosion Barrier Properties of Hybrid Sol-Gel Coatings: Application to the Protection of AA2024-T3 Alloys. Journal of Sol-Gel Science and Technology, 82, 801-816.

[21] Rajath Varma, P.C., Colreavy, J., Cassidy, J., Oubaha, M., McDonagh, C. and Duffy, B. (2010) Corrosion Protection of AA 2024-T3 Aluminium Alloys using 3, 4-Diaminobenzoic Acid Chelated Zirconium-Silane Hybrid Sol-Gels. Thin Solid Films, 518, 5753-5761

[22] Rajath Varma, P.C., Colreavy, J., Cassidy, J., Oubaha, M., Duffy, B. and McDonagh, C. (2009) Effect of Organic Chelates on the Performance of Hybrid Sol-Gel Coated AA 2024-T3 Aluminium Alloys. Progress in Organic Coatings, 66, 406-411.

[23] Oubaha, M., Smaihi, M., Etienne, P., Coudray, P. and Moreau, Y. (2003) Spectroscopic Characterization of Intrinsic Losses in an Organic-Inorganic Hybrid Waveguide Synthesized by the Sol-Gel Process. Journal of Non-Crystalline Solids, 318, 305-313. https://doi.org/10.1016/S0022-3093(02)01889-6

[24] Xu, R. (2015) Light Scattering: A Review of Particle Characterization Applications. Particuology, 18, 11-21. https://doi.org/10.1016/j.partic.2014.05.002

[25] Blanchard, J., In, M., Schaudel, B. and Sanchez, C. (1998) Hydrolysis and Condensation Reactions of Transition Metal Alkoxides: Calorimetric Study and Evaluation of the Extent of Reaction. European Journal of Inorganic Chemistry, 8, 1115-1127. https://doi.org/10.1002/(SICI)1099-0682(199808)1998:8<1115::AID-EJIC1115>3.0. $\mathrm{CO} ; 2-\mathrm{N}$

[26] Delattre, L. and Babonneau, F. (1997) ${ }^{17} \mathrm{O}$ Solution NMR Characterization of the Preparation of Sol-Gel Derived $\mathrm{SiO}_{2} / \mathrm{TiO}_{2}$ and $\mathrm{SiO}_{2} / \mathrm{ZrO}_{2}$ Glasses. Chemistry of Materials, 9, 2385-2394. https://doi.org/10.1021/cm970372f

[27] Charleux, B., Copéret, C. and Lacôte, E. (2015) Chemistry of Organo-Hybrids: Synthesis and Characterization of Functional Nano-Objects. Johns Wiley \& Sons, Hoboken. https://doi.org/10.1002/9781118870068

[28] Morrow, B.A. and McFarlan, A.J. (1992) Surface Vibrational Modes of Silanol Groups on Silica. The Journal of Physical Chemistry, 96, 1395-1400. 
https://doi.org/10.1021/j100182a068

[29] Rosario Elvira, M., Alejandra Mazo, M., Tamayo, A., Rubio, F., Rubio, J. and Oteo, J.L. (2013) Study and Characterization of Organically Modified Silica-Zirconia Anti-Graffiti Coatings Obtained by Sol-Gel. Journal of Chemistry and Chemical Engineering, 7, 120-131.

[30] Pickup, D.M., Mountjoy, G., Wallidge, G.W., Newport, R.J. and Smith, M.E. (1999) Structure of $\left(\mathrm{ZrO}_{2}\right)_{\mathrm{x}}\left(\mathrm{SiO}_{2}\right)_{1-\mathrm{x}} \mathrm{xerogels}(\mathrm{x}=0.1,0.2,0.3$ and 0.4$)$ from FTIR, ${ }^{29} \mathrm{Si}$ and ${ }^{17} \mathrm{O}$ MAS NMR and EXAFS. Physical Chemistry Chemical Physics, 1, 2527-2533. https://doi.org/10.1039/a901401b

[31] Hanuhov, T., Asulin, E. and Gvishi, R. (2017) Evaluation of Opto-Mechanical Properties of UV-Cured and Thermally-Cured Sol-Gel Hybrids Monoliths as a Function of Organic Content and Curing Process. Journal of Non-Crystalline Solids, 471, 301-311. https://doi.org/10.1016/j.jnoncrysol.2017.05.043

[32] Z. Weihua, Z. Gaoyang, C. Zhiming, (2003) Photosensitive PZT Gel Films and Their Preparation for Fine Patterning. Materials Science and Engineering: B, 99, 168-172. https://doi.org/10.1016/S0921-5107(02)00478-6

[33] Zheludkevich, M.L., Serra, R., Montemor, M.F., Yasakau, K.A., Miranda Salvado, I.M. and Ferreira, M.G.S. (2005) Nanostructured Sol-Gel Coatings Doped with Cerium Nitrate as Pre-Treatments for AA2024-T3: Corrosion Protection Performance. Electrochimica Acta, 51, 208-217. https://doi.org/10.1016/j.electacta.2005.04.021 